\title{
PENGARUH BONANG SEKATEN PADA BONANG BARUNG: KAJIAN GARAP KARAWITAN
}

\author{
Teguh $^{\mathrm{a}, 1, *}$, Widiandari ${ }^{\mathrm{b}, 2}$ \\ ${ }^{a}$ Fakultas Seni Pertunjukan Institut Seni Indonesia Yogyakarta \\ ${ }^{\mathrm{b}}$ Fakultas Seni Pertunjukan Institut Seni Indonesia Yogyakarta \\ ${ }^{1}$ teguhwidodosolo@gmail.com ${ }^{2}{ }^{2}$ widiandariii@gmail.com
}

Received 9 Dec 2020; accepted 13 Dec 2020; published 30 Juli 2021

\begin{abstract}
Bonang barung is one of the ricikan found in the gamelan sekaten and gamelan ageng. It functions as ricikan garap, it means that bonang barung must work on balungan gending. The techniques or motifs of the wasps include: mipil, gembyang, imbal, and klenangan. Of the several wasps, many of the mipil wasps are adopted from the bonang sekaten wasps. This study aims to determine the relationship between wasp motifs and balungan gending. The method used is descriptive analytical. Data was collected through interviews with several interviewees. In addition to interviews, the literature study was also carried out based on references about musical knowledge and several writings related to the material. The final result of this study shows that there are two things happen because of the effect of bonang sekaten wasp on the bonang barung wasp, namely adoption and adaptation.
\end{abstract}

\section{KEYWORDS}

Bonang sekaten, bonang barung, wasp motif.
This is an open access article under the $C C-B Y-S A$ license

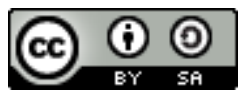

\section{Pengantar}

Di dalam dunia karawitan gaya Surakarta, selain terdapat perangkat gamelan ageng juga terdapat perangkat gamelan pakurmatan. Yang termasuk perangkat gamelan pakurmatan adalah Gamelan Kodhok Ngorek, Monggang, Carabalen, dan perangkat Gamelan Sekaten. Gamelan Ageng di dalam dunia gamelan mempunyai dua sistem laras yaitu laras slendro dan laras pelog. Kedua laras tersebut tercermin dalam ricikan. Dengan demikian dalam jenis gamelan ada dua kelompok ricikan yaitu berlaras slendro dan pelog. Berdasarkan penjelasan itu dapat dipahami bahwa Gamelan Ageng adalah perangkat gamelan yang terdiri dari dua laras yaitu laras slendro dan laras pelog. Dalam perangkat Gamelan Ageng setidak-tidaknya terdapat 22 jenis ricikan, salah satu ricikan itu adalah Bonang barung.

Masing-masing gamelan khususnya yang ada di Keraton Kasunanan Surakarta telah diatur penggunaannya, disesuaikan dengan upacara yang ada di dalam Keraton. Salah satu contoh adalah Gamelan Sekaten ditabuh sekali dalam satu tahun yaitu pada upacara Maulud Nabi. Gamelan ini ditempatkan di pagongan halaman Masjid Agung dan ditabuh selama tujuh hari dan tujuh malam. Salah satu ricikan yang terdapat pada perangkat Gamelan Sekaten adalah ricikan bonang. Namun bonang sekaten tidak ditabuh seorang pengrawit, melainkan ditabuh oleh dua atau tiga orang pengrawit. Bonang yang nadanya alit atau lazim disebut bonang lanang ditabuh satu orang pengrawit, sedangkan bonang yang nadanya ageng yang lazim disebut bonang wadon ditabuh oleh satu atau dua orang pengrawit. Pada nada-nada kecil atau bonang lanang berfungsi sebagai bonang layaknya bonang barung gamelan ageng, sedangkan nada ageng atau wadon berfungsi sebagai bangge atau nibani.

Bonang sekaten mempunyai fungsi yang sangat penting yaitu (1) menyajikan racikan sebelum gending dan, (2) sebagai pamurba lagu serta, (3) bertugas memperindah gending dengan segala motif tabuhannya. Bonang sekaten hanya mempunyai nada satu deret, tidak seperti Bonang gamelan ageng, 
oleh karena itu seorang pembonang atau penabuh bonang sekaten harus kreatif dalam menggarap balungan. Keterbatasan jumlah nada inilah yang menuntut pengrawit atau pembonang harus kreatif, tujuannya adalah supaya sajian gending lebih enak, hidup dan menarik. Penjelasan tersebut dapat dipahami, bahwa karena keterbatasan sarana dalam hal ini adalah nada-nada, oleh karena itu menuntut seorang pembonang gamelan sekaten selalu kreatif. Kreatif disini terutama tentang memilih wiled dan teknik serta motif bonangannya.

Fakta menunjukkan bahwa sampai saat sekarang ini, sebenarnya banyak teknik atau motif tabuhan bonang sekaten yang disajikan atau ditabuh pada tabuhan bonang perangkat gamelan ageng, tetapi pembonang atau pengrawit penabuh bonang itu sendiri umumnya tidak mengetahui bahwa apa yang dia sajikan itu sebenarnya pengaruh dari tabuhan bonang sekaten. Bahkan pada saat penulis mencermati kuliah praktik karawitan gaya Surakarta, baik karawitan Surakarta alit, tengahan, maupun ageng, ada beberapa dosen tidak menjelaskan secara rinci tentang teknik tabuhan Bonang kepada para mahasiswa. Salah satu contoh adalah, ketika pengajar memberikan penjelasan tentang grambyangan bonang laras pelog pathet lima. Dalam dunia pendidikan formal apalagi di Jurusan Karawitan Fakultas Seni Pertunjukan Institut Seni Indonesia, mahasiswa sebagai calon sarjana sekaligus sebagai seniman karawitan harus dibekali ilmu dan pengetahuan yang cukup. Dengan demikian kelak para mahasiswa bisa memberikan pengetahuan kepada masyarakat.

Seperti diketahui bahwa gending yang tidak sedang ditabuh atau dibunyikan itu hanyalah berujud angka-angka yang dijejer, angka itu yang kemudian terkenal atau lazim disebut balungan gending. Setelah menjadi gending apapun bentuknya, apakah bentuk gending kethukloro, papat, ladrang, ketawang dan lain-lainnya lalu kemudian diberi laras dan patet sebagai kelengkapan dari sebuah gending.Tradisi selama ini tidak pernah ada diskripsi tentang garap gending. Artinya bahwa garap gending itu sangat tergantung kepada pengrawitnya, dengan kata lain pengrawit mempunyai otoritas dalam hal garap gending sangat luas, sehingga sangat dimungkinkan dengan gending yang sama tetapi digarap pengrawit yang berbeda hasil garapnya berbeda pula. Dalam dunia karawitan khususnya tentang garap, tidak ada istilah salah dan benar yang ada hanyalah enak dan tidak enak.

Atas dasar ini maka sangat menarik untuk dikaji agar dapat diketemukan penjelasannya dan selanjutnya menjadikan peningkatan kualitas di dalam penyajian seni karawitan yang biasanya berdasarkan "angon rasa" menjadi "angon ngelmu". Kolaborasi garap ricikan yang satu dengan ricikan lainnya akan menimbulkan harmoni dalam sebuah sajian gending, sehingga ketepatan pemilihan motif tabuhan bonang menjadi sangat penting, begitu pula sebaliknya tanpa alasan yang mendasar sajian sebuah gending menjadi hambar atau bahkan tidak berkualitas, cebleh, sangli, ora mungguh dan seterusnya..

\section{Jenis Tabuhan Bonang Sekaten}

Ketika penulis berbincang-bincang dengan K.R.R.A. Saptodiningrat mendapatkan penjelasan sebagai berikut:

Jenis tabuhan bonang sekatén kuwi ora akèh mung ana papat yakuwi mbalung, gembyang, mipil låmbå karo mipil rangkep. Jenis tabuhan bonang sekatèn ora akèh, mergå gendingé kuwi mung digarap tekan irama dados. Ing mångkå kabèh tabuhan kuwi mesthi ånå gayutané karo irama, mulå tabuhané yo mung sithik. Kåyå sing wis tak aturké kuwi mau (Wawancara tanggal 20 Agustus 2020 di Makamhaji Kartosuro).

Terjemahan bebas:

Jenis tabuhan bonang sekaten itu tidak banyak, hanya ada empat jenis tabuhan yaitu mbalung, gembyang, mipil lamba dan mipil rangkep. Jenis tabuhan Bonang sekaten itu tidak banyak, karena semua gending sekaten hanya digarap sampai irama dadi padahal semua tabuhan itu apapun ricikannya pasti ada hubungannya dengan irama. Oleh sebab itu maka jenis tabuhan Bonang sekaten hanya sedikit, tidak seperti tabuhan bonang barung seperti yang sudah saya katakan tadi. 
Penjelasan seperti tersebut di atas dapat dimengerti bahwa jenis tabuhan bonang sekaten pada dasarnya hanya ada empat yaitu mbalung, gembyang, mipil lamba, dan mipil rangkep.

\section{Mbalung}

Tabuhan mbalung pada dasarnya hanya digunakan untuk keperluan grambyangan dan racikan. Perlu diketahui bahwa semua gending yang dimainkan pada sekaten, baik gending wajib maupun gending-gending srambahan harus dimulai dari racikan. Dan racikan ini sebagai pengganti bagian merong, oleh karena itu maka sajian gending sekaten tidak menyajikan merong, dengan demikian hanya bagian inggah saja yang dimainkan.

Contoh tabuhan mbalung adalah sebagai berikut:

Grambyangan laras pelog patet lima

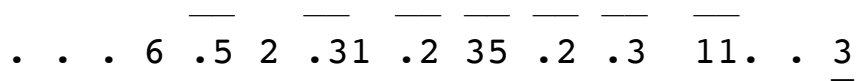

Racikan pelog nem bagian pertama

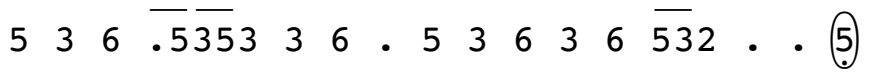

\section{Nggembyang}

Tabuhan gembyang digunakan untuk menggarap pada balungan kembar dan pada bagian irama tanggung laya seseg yang lazim disebut sabetan merupakan ciri khas permainan tabuhan sekaten. Contoh sebagai berikut:

-Balungan kembar

Balungan:

$$
\begin{array}{llllllll}
2 & 2 & \cdot & 2 & 2 & 3 & 5 & 6
\end{array}
$$

Bonang:

$2 \ldots 2 . .2 \ldots 2 . .2 \ldots 2.32 \ldots 32.565 \ldots 65$.

-Irama tanggung laya seseg lazim disebut sabetan

Balungan:

$2 \cdot 1 \cdot 2 \cdot 3 \cdot 2 \cdot 1 \cdot 2 \cdot \hat{6}$

Bonang :

$1 \cdot 1 \cdot 3 \cdot 3 \cdot 1 \cdot 1 \cdot 6 \cdot 6 \cdot$

\section{Mipil Lamba}

Balungan:
2
12
3
21
6 
Bonang :

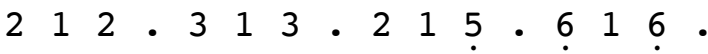

\section{Mipil Rangkep}

Balungan:

$$
\begin{array}{llllllll}
2 & 1 & 2 & 3 & 2 & 1 & 2 & 6
\end{array}
$$

Bonang: . 12 . 12 .32 .32 . 12 . 12 . 15 61

\section{Jenis-jenis Tabuhan Bonang Barung}

Sumarsam dalam bukunya yang berjudul Hayatan Gamelan: Kedalaman Lagu, Teori, Perspektif menjelaskan, bahwa pada dasarnya bonang mempunyai dua jenis permainan pokok, pipilan atau mipil dan imbal-imbalan. Pipilan yang arti sebenarnya adalah mengambil satu persatu atau bisa juga disebut memainkan nada tunggal secara bergantian. Dan Imbal-imbalan arti sebenarnya adalah kembali bergantian atau bergantian isi mengisi (2002: 57-58). Berikut adalah jenis-jenis tabuhan Bonang barung pada karawitan gaya Surakarta: 1. Mbalung, 2. Mipil, 3. Gembyang, 4.Imbal 5. Klenangan, dan 6. Sekaran.

Penjelasan penggunaan tabuhan bonang barung terhadap garap gending, terutama gendinggending tradisi gaya Surakarta adalah sebagai berikut:

\section{Mbalung}

Tabuhan mbalung digunakan untuk buka dan dua gatra setelah gong buka pada bentuk gending tengahan dan gending ageng. Contoh sebagai berikut,

-Buka Lancaran Tropongan Laras Pelog Patet Lima

Buka:

. $\begin{array}{lllllllllllllll}3 & 5 & 6 & 7 & 6 & 5 & 6 & 5 & 4 & 2 & 4 & 2 & 1 & 6 & \text { (5) }\end{array}$

Bonang :

. $\begin{array}{lllllllllllllll}3 & 5 & 6 & 7 & 6 & 5 & 6 & 5 & 4 & 2 & 4 & 2 & 1 & 6 & \text { (5) }\end{array}$

-Gending Gambirsawit kethuk 2 kerep minggah 4 laras slendro pathet sanga gatra pertama dan kedua setelah gong buka:

Balungan:

. $352 \cdot 356 \quad 22 \cdot . \quad 2321$

Bonang :

• 35 5 2 - 3 5 6 $222.22 \ldots 23232121$ 


\section{Mipil}

\section{-Mipil lamba}

Umumnya teknik pipilan bonang berfungsi sebagai lagu penuntun ricikan saron. Bonang menunjukan penabuh saron nada-nada yang akan datang dengan cara mendahului sepasang nada balungan. Apapun bentuk gendingnya, bilamana gending dimainkan dengan menggunakan irama tanggung, maka tabuhan bonang barung menggunakan jenis tabuhan mipil lamba. Tabuhan ini ditandai satu per dua (1/2) yang artinya setiap satu tabuhan balungan mendapatkan dua tabuhan bonang barung. Contoh,

Balungan: $2 \quad 1 \quad 2 \quad 3$

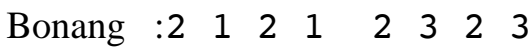

-Mipil rangkep

Mipil rangkep digunakan untuk irama dadi atau dados, baik bentuk gending alit, tengahan maupun gending ageng bila digarap menggunakan irama dadi, maka tabuhan Bonang menggunakan mipil rangkep. Diberi simbol 1/4 yang artinya setiap satu tabuhan balungan mendapatkan empat tabuhan Bonang barung.

Contoh mipil rangkep balungan mlaku:

$\begin{array}{lllll}\text { Balungan: } & 2 & 1 & 2 & 3\end{array}$

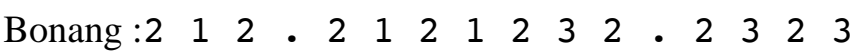

Contoh mipil rangkep balungan nibani:

Balungan: $\quad$ • $\quad 5 \quad 3$

Bonang:. 5.2255 .0252 .3353

\section{Gembyang}

Gembyang mempunyai pengertian menabuh dua buah nada secara bersamaan, dan nada tersebut berjaraksatu gembyangan. Seleh tabuhan Bonang mendahului seleh balungan dalam satu gatra penuh. Dan dimainkan untuk menggarap balungan nada kembar.

Contoh:

Balungan: $\quad 3 \quad 3 \quad$.

Bonang:3 $3 \underline{3} \cdot 3 \underline{3} \cdot \cdot 3 \quad 3 \underline{3} \cdot 3 \underline{3} \cdot \cdot$

\section{Imbal}

Imbal mempunyai arti variasi pukulan bergantian antara bonang barung dengan bonang penerus. Teknik ini dimainkan bilamana gending digarap menggunakan kendang ciblon dalam irama wiled. Contoh:

Balungan 
Bonang barung:

$$
.1 .3 .1 .3 .1 .3 .1 .3 \quad 216 \underline{3.6 .1 .2161612}
$$

Bonang penerus:

$$
2 \cdot 5 \cdot 2 \cdot 5 \cdot 2 \cdot 5 \cdot 2 \cdot 5 . \quad 6123535321612.12
$$

\section{Klenangan}

Klenangan mempunyai arti variasi pukulan bergantian antara bonang barung dengan bonang penerus dan nada yang ditabuh adalah 4 nada yang saling berurutan. Ketika dimainkan bersama maka menghasilkan suara $1235,2356,5612$, ataupun yang lainnya secara berulang-ulang.

Salah satu contohnya:

Bonang barung :

$$
\text { . } 56 \text {. } 56 \text {. } 56 \text {. } 56 \text {. } 56
$$

Bonang penerus:

$23 \cdot .23 \cdot .23 \cdot .23 \cdot$.

\section{Sekaran}

Sekaran merupakan variasi pukulan yang dimainkan oleh bonang barung maupun bonang penerus setelah melakukan pancer pada imbal. Sekaran yang digunakan sesuai dengan nada seleh balungan. Teknik ini dimainkan bilamana gending digarap menggunakan kendang ciblon dalam irama wiled.

Balungan

$$
3 \quad \cdot \quad 2
$$

Bonang barung :

$$
.1 .3 .1 .3 .1 .3 .1 .3 \quad 2163.6 .1 .2161612
$$

Bonang penerus:

$$
2 \cdot 5 \cdot 2 \cdot 5 \cdot 2 \cdot 5 \cdot 2 \cdot 5 . \quad 6123535321612.12
$$

\section{Pengaruh Tabuhan Bonang Sekaten pada Bonang Barung}

Hasil penelitian tentang pengaruh Bonang sekaten pada bonang barung setelah diidentifikasi pada dasarnya dapat dibagi menjadi dua, yaitu pertama berupa adopsi dan adaptasi.

\section{Adopsi}

Adopsi yang dimaksud dalam penelitian ini adalah jenis tabuhan bonang barung yang mendapat pengaruh dari tabuhan bonang sekaten atau dengan kata lain sebelum terpengaruh tabuhan bonang sekaten, di dalam tabuhan bonang barung belum pernah ada sebelumnya. Contoh hasil adopsi yang ada, salah satunya adalah pada grambyangan.

a. Grambyangan

Grambyangan adalah suatu melodi lagu yang relatif pendek. Fungsi grambyangan antara lain:

(1) Sebagai isyarat atau ajakan kepada sesama pengrawit bahwa gending segera akan dimulai dan,

(2) Grambyangan dimainkan bilamana gending yang dimainkan jenis gending bonang dan gendinggending bentuk Lancaran. Berikut adalah grambyangan bonang barung sebagai berikut: 
-Grambyangan wantah

$\begin{array}{llllllllllllllll}2 & 3 & 5 & \cdot & 3 & 6 & 5 & 3 & 5 & \cdot & 2 & 6 & 5 & 5 & 2 & 5\end{array}$

-Grambyangan jugag

6.5525

Grambyangan bonang barung baik wantah maupun jugag seperti tersebut di atas, dipergunakan untuk semua laras dan semua patet. Dengan demikian grambyangan tidak memberi informasi patet gending yang akan dimainkan.

Selanjutnya K.R.R.A Saptodiningrat menjelaskan perihal grambyangan bonang barung sebagai berikut:

Mbiyèn jaman aku sekolah néng Konservatori, Bapak-bapak nék ngajari grambyangan bonang laras sléndro lan pélog, patheté apa waé yo mung séléh 5 (ma) gêdhé, mêrga grambyangan bonang kui ora nuduhaké pathêt kaya déné grambyangan gêndèr lan sênggrèngan rêbab. Banjur ana perkembangan grambyangan bonang mligi laras pélog pathêt limå såkå grambyangan bonang sekatén nanging mung bagian ngarêp sing dinggo (Wawancara tanggal 10 Juli 2019 di Makamhaji Kartosuro).

Terjemahan bebas:

Dulu pada saat saya sekolah di Konservatori, Bapak-bapak jika mengajar tentang grambyangan bonang laras slendro dan pelog, semua patet hanya satu grambyangan seleh 5 ( $\mathrm{ma}$ ) gedhe, karena grambyangan bonang tidak menunjukkan laras dan patet seperti grambyangan gender dan senggrengan rebab. Kemudian ada perkembangan musikal grambyangan bonang laras pelog patet lima menggunakan grambyangan bonang sekaten patet lima tetapi hanya bagian depan yang digunakan.

Contoh grambyangan laras pelog pathet lima seperti sebagai berikut:

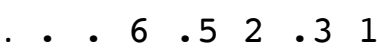

Grambyangan untuk laras pelog pathet lima seperti di atas, sebenarnya berasal dari grambyangan wantah pada bonang sekaten, hanya diambil setengahnya di bagian depan. Alasannya adalah seleh 1 (penunggul) merupakan nada dominan di dalam laras pelog pathet lima. Sedangkan grambyangan laras pelog lima yang utuh atau wantah adalah sebagai berikut:

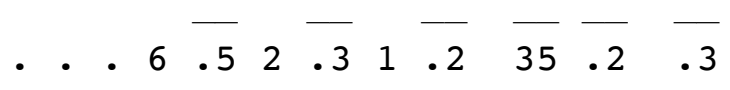

$\overline{11} \cdot$. 3

Keterangan lain yang berhubungan dengan tabuhan bonang sekaten K.R.T. Radyo Adi Nagoro mengatakan bahwa motif tabuhan bonang sekaten pada sajian klenengan pertama-tama yang mempopulerkan adalah maestro karawitan yakni K.R.T. Widodonagoro, dalam dunia karawitan gaya Solo terkenal dengan sebutan Mbah Mloyo. Mbah Mloyo merupakan pengrawit abdi dalem Keraton Kasunanan Surakarta, sangat terkenal jika memainkan ricikan Bonang barung. Karena beliau juga pembonang Sekaten, maka ketika menabuh bonang barung pada sajian klenengan, banyak memainkan motif bonangan sekaten. Oleh karena yang memainkan seorang maestro Bonang barung, maka para pengrawit yang lain sering menirukan apa yang dilakukan Mbah Mloyo (Wawancara tanggal 12 Desember 2019 di Klaten). 


\section{b. Gembyang}

Gembyang adalah menabuh dua nada ageng dan alit secara bersamaan.

\section{Contoh:}

Balungan $\quad: \quad 3 \quad 3 \quad$ •

Bonang barung : 333 . 33.. 333. $33 \ldots$

Bonang sekaten: $3 \ldots 3$..3. 3.3 .3

Balungan:

$\begin{array}{lllllll}3 & 3 & 6 & 5 & 3 & 2\end{array}$

Bonang barung:

333. 33.. 333. 33..656. 6565323.3232

Bonang sekaten:

$3 . .3 \quad \ldots 3 . .3 .3 . .36 .636 .56 .23 .23$.

c. Inggah Gending Raranjala kethuk 2 arang minggah 4 laras pelog pathet lima, kenong pertama dan kedua. Adopsinya terletak pada gatra ketiga, digarap menggunakan mipil cegatan. Umumnya mipil cegatan digunakan untuk menggarap balungan nibani.

Balungan:

$\begin{array}{llllllll} & 2 & 4 & 1 & \text { • } & 2 & 4 & 5\end{array}$

Bonang:

$.21 \ldots 21.414 \ldots 14 \ldots 21 \ldots 21.464 .54 .5$

Balungan:

$\begin{array}{llllllll}4 & 6 & 4 & 5 & 4 & 2 & 4 & 1\end{array}$

Bonang:

$645664 . .646 .54 .5 .24 \ldots 24.2411 .1 \ldots$

\section{Adaptasi}

Adaptasi yang dimaksud dalam konteks ini adalah mengambil atau meniru motif tabuhan yang ada pada tabuhan bonang sekaten yang kemudian diaplikasikan ke dalam tabuhan bonang barung. Motif yang dimaksud dalam penelitian ini adalah isian tabuhan bonang dalam menggarap gatra balungan gending. Karena isian tersebut disebut cengkok kurang tepat, sebab cengkok secara tradisi adalah melodi lagu yang sudah pasti, seperti misalnya cengkok ayu kuning, puthut gelut, kacaryan, jarik kawung dua lolo dan lain sebagainya. Sedangkan motif tabuhan bonang sifatnya tidak ajeg. Di bawah ini adalah motif tabuhan bonang sekaten yang sering ditabuh pada bonang barung adalah sebagai berikut: 
a. Mipil rangkep pada balungan mlaku atau mlampah

Balungan:

$$
\begin{array}{llllllll}
2 & 3 & 2 & 1 & 6 & 5 & 3 & 5
\end{array}
$$

Bonang:

$.32 \ldots 32 \ldots 12 \ldots 12.636 \ldots 56.563 \ldots 56$.

b. Gembyang untuk balungan kembar atau gantungan

Balungan : $2 \quad 2$

Bonang

$$
: 2 \ldots 2 \quad \ldots 2.2 \ldots 2 \ldots 2
$$

c. Mipil rangkep untuk balungan Nibani

Balungan:

Bonang:

$653225 \ldots 252 \cdot 35 \cdot 3 \cdot 65336 \cdot 363 \cdot 56 \cdot 5$

d. Balungan Ngracik, petikan inggah Gending Klentung kethuk 4 arang minggah 8 laras pelog pathet lima, kenong pertama

Balungan:

$$
\begin{array}{llllllll}
2 & 1 & 2 & \cdot & 2 & 1 & 6 & 54
\end{array}
$$

Bonang:

$.12 \ldots 12 \ldots 12 \ldots 12 \ldots 12 \ldots 121.56 \ldots 56$.

Balungan:

$$
\begin{array}{llllllll}
54 & \overline{54} & \overline{54} & \overline{54} & \overline{54} & \overline{54} & 6 & 1
\end{array}
$$

Bonang:

$.54 \ldots 54 \ldots 54 \ldots 54 \ldots 54 \ldots 54 \ldots 16 \ldots 16$. . .

Balungan:

$$
\begin{array}{llllllll}
2 & 1 & 2 & \cdot & 2 & 1 & 6 & 54
\end{array}
$$

Bonang:

$.12 \ldots 12 \ldots 12 \ldots 12 \ldots 12 \ldots 121.56 \ldots 56$ 
Balungan:

$$
54 \quad 54 \quad 54 \quad 54 \quad 54 \quad 54 \quad 6 \quad 1
$$

Bonang:

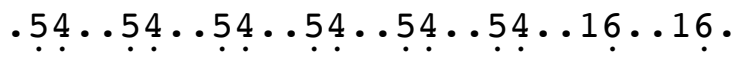

\section{e. Balungan pin mundur}

Perlu diketahui bahwa susunan balungan pin walaupun tidak terdapat tabuhan balungan secara fisik, namun pin merupakan kepanjangan atau penggandaan harga dari balungan sebelumnya. Contoh balungan pin mundur dapat dilihat dari petikan inggah Gending Bedaya kethuk 4 awis minggah 8 laras pelog pathet barang, kenong keempat. Sebagai berikut:

Balungan:

Bonang:

$2 \ldots 2.2 .3 \ldots 3 \ldots 3.2 \ldots 2 \ldots 2.7227772$.

Balungan:

$\begin{array}{llllllll}6 & \cdot & 6 & 7 & 6 & 5 & 3 & 5\end{array}$

Bonang:

$6 \ldots 6.6 .676 \ldots 76.656 \cdot .56 \cdot 563 \cdot 56 \cdot 5$

\section{Kesimpulan}

Berdasarkan uraian yang telah dipaparkan, pengaruh tabuhan bonang sekaten pada bonang barung dapat disimpulkan sebagai berikut.

Dalam perangkat, baik gamelan ageng maupun gamelan sekaten, diketahui bahwa bentuk bonang tergolong dalam bentuk pencon. Ukuran bonang sekaten lebih besar dari pada ukuran bonang barung. Karena ukurannya besar maka penabuh bonang sekaten memerlukan dua atau tiga pengrawit. Deret nada kecil dimainkan oleh satu pengrawit dan deret nada besar dimainkan satu atau dua pengrawit. Bonang adalah ricikan berupa dua baris rangkaian gong-gong kecil berposisi horisontal, diletakkan pada tali yang ditegangkan pada bingkai kayu. Bonang slendro biasanya meliputi satu oktaf dan empat nada, kadang kala dua nada ditambahkannya. Bonang pelog wilayah nadanya meliputi wilayah nada satu oktaf dan enam nada.

Fungsi bonang dalam permainan gending pada dasarnya ada dua, yakni sebagai pamurba lagu manakala gending yang dimainkan berjenis gending bonang dan fungsinya berubah menjadi pamangku lagu ketika yang dimainkan gending rebab dan atau gending gender atau gending yang lain.

Teknik tabuhan bonang barung yaitu, (1) Mbalung, (2) Mipil lamba, (3) Mipil rangkep, (4) Gembyang, (5) Imbal dan, (6) Klenangan. Masing-masing penggunaan dan tekniknya telah dipaparkan pada Bab III. Sedangkan teknik tabuhan bonang sekaten diketahui antara lain, (1) Mbalung, (2) Mipil lamba, (3) Mipil rangkep, serta (4) Gembyang. Teknik tabuhan bonang sekaten hanya ada empat, karena penyajian sekaten tidak menggunakan irama wiled, dengan demikian irama yang ada pada penyajian sekaten yaitu irama tanggung dan irama dadi atau dados.

Teknik tabuhan mipil rangkep bonang sekaten isiannya relatif sedikit, hal ini ada pengaruh dari bentuk fisik dan penyajian sekaten yang membutuhkan tenaga ekstra. Ditambah pula bahwa penyajian sekaten menjelang suwuk selalu ada permainan tabuhan soran dengan irama tanggung laya seseg, oleh karenanya penabuh bonang 
harus bisa menghemat atau mengelola tenaga dengan baik. Selanjutnya pada teknik tabuhan gembyang hanya satu nada alasannya adalah bahwa bonang sekaten hanya terdiri dari tujuh nada dengan wilayah oktaf tinggi atau kecil.

Motif tabuhan bonang sekaten pada sajian klenengan pertama-tama dipopulerkan oleh maestro karawitan K.R.T. Widodonagoro, dalam dunia karawitan gaya Surakarta terkenal dengan sebutan Mbah Mloyo. Mbah Mloyo merupakan pengrawit abdi dalem Keraton Kasunanan Surakarta, sangat terkenal jika memainkan ricikan bonang barung. Karena beliau juga pembonang sekaten, maka ketika menabuh bonang barung pada sajian klenengan, banyak memainkan motif bonangan sekaten. Oleh karena yang memainkan seorang maestro bonang barung, maka para pengrawit yang lain sering menirukan apa yang dilakukan Mbah Mloyo.

Selain faktor di atas, fakta juga menunjukkan bahwa sampai saat sekarang ini, sebenarnya banyak teknik atau motif tabuhan bonang sekaten yang disajikan atau ditabuh pada tabuhan bonang perangkat gamelan ageng, tetapi pembonang atau pengrawit penabuh bonang itu sendiri umumnya tidak mengetahui bahwa apa yang dia sajikan itu sebenarnya pengaruh dari tabuhan bonang sekaten. Bahkan pada saat penulis mencermati kuliah praktik karawitan gaya Surakarta, baik karawitan Surakarta alit, tengahan, maupun ageng ada beberapa dosen tidak menjelaskan secara rinci tentang teknik tabuhan bonang kepada para mahasiswa.

Hasil penelitian ini mendapatkan dua klasifikasi pengaruh tabuhan bonang sekaten pada tabuhan bonang barung, yaitu adopsi dan adaptasi. Dalam konteks ini, adopsi yang dimaksud adalah jenis tabuhan bonang barung yang mendapat meniru sama persis dari tabuhan bonang sekaten atau dengan kata lain sebelum terpengaruh tabuhan bonang sekaten, di dalam tabuhan bonang barung belum pernah ada sebelumnya. Sedangkan adaptasi adalah mengambil atau meniru motif tabuhan yang ada pada tabuhan bonang sekaten yang kemudian diaplikasikan ke dalam tabuhan bonang barung.

\section{KEPUSTAKAN}

Djumadi. 1975. Titilaras Rebaban Jilid I, Akademi Seni Karawitan Indonesia, Surakarta.

Hadi, Sutrisno. 1991. "Pokok - Pokok Metodologi Penelitian Ilmiah" Sebuah Naskah dalam rangka Penataran Metode Penelitian Tenaga Pengajar ISI Yogyakarta tanggal 5 dan 6 Agustus 1991.

Hastanto, Sri. 2009. Konsep Pathet Dalam Karawitan Jawa, Program Pascasarjana bekerjasama dengan ISI Press, Surakarta.

John W, Creswell. 2014. RESEARCH DESIGN Pendekatan Kualitatif, kuantitatif, dan Mixed, Penerbit Pustaka Pelajar Yogyakarta, Yogyakarta.

Kartining, "Bonang Barung Dalam Penyajian Ketawang Gending Elo-elo Kalibeber Suatu Kajian Musikologis" (Skripsi sebagai syarat untuk mencapai derajat Sarjana S-1 Program Studi Karawitan Fakultas Seni Pertunjukan Institut Seni Indonesia Yogyakarta, 2001)

Koentjaraningrat. 1991. Metode-Metode Penelitian Masyarakat, Gramedia, Jakarta.

Kutha Ratna, Nyoman. 2010. Metodologi Penelitian Kajian Budaya Dan Ilmu Sosial Humaniora Pada Umumnya, Pustaka Pelajar Yogyakarta, Yogyakarta.

Martopangrawit, R.1. 1975. Pengetahuan Karawitan Jilid I dan II, Akademi Seni Karawitan Indonesia Surakarta.

Mloyowidodo. 1973. Balungan Gending Jilid I, II, III, Bagian Reserch Konservatori Karawitan Indonesia Surakarta.

Moleong, Lexy J. 2014. Metodologi Penelitian Kualitatif, Penerbit PT. Remaja Rosdakarya Bandung, Bandung.

Nasir, Moh. 1988. Metode Penelitian, Ghalia, Jakarta, Indonesia.

Nawawi, Hadari. 1987. Metodologi Penelitian Bidang Sosial, Gajah Mada University Press, Yogyakarta.

Prajapangrawit, R.Ng. 1990. Serat Sujarah Utawi Riwayating Gamelan Wedhapradangga, STSI Surakarta dengan Fort Foundation, Surakarta.

Rustopo. 2014. Perkembangan Gending-Gending Gaya Surakarta 1950-2000-an, ISI Press Solo, Surakarta. 
Soeroso. 1983. Gamelan B, Departemen Pendidikan dan Kebudayaan Direktorat Jendral Pendidikan Dasar dan Menengah, Direktorat Jendral Pendidikan Menengah Kejuruan, Proyek Pengadaan Buku Pendidikan Menengah Kejuruan, Jakarta.

Sumarsam. 2002. Hayatan Gamelan Pendalaman Lagu, Teori, dan Persepektif, STSI Press, Surakarta.

Supanggah, Rahayu. 2002. Bothekan Karawitan I, Ford Foundation dan Masyarakat Seni Pertunjukan Indonesia, Surakarta.

Press, Surakarta.

2009. Bothekan Karawitan II: GARAP, Program Pascasarjana bekerja sama dengan ISI 2011. Dunia Pewayangan di Hati Seorang Pengrawit, ISI Press Solo, Surakarta.

Suparno, Slamet. 2006. Pendekatan Sosiologis, dalam Penelitian Karawitan ISI Surakarta, Surakarta.

Suryabranta, Sumardi. 1988. Metode Penelitian, CV. Rajawali, Jakarta.

Utami Ciptaningsih, "Komparasi Rambu Dan Rangkung Sekaten Surakarta Dan Yogyakarta” (Skripsi sebagai syarat untuk mencapai derajat Sarjana S-1 Program Studi Karawitan Fakultas Seni Pertunjukan Institut Seni Indonesia Yogyakarta, 2003)

Waridi. 2008. Gagasan \& Kekaryaan Tiga Empu Karawitan, Penerbit Etnoteater Publisher, Bacc Kota Bandung bekerja sama dengan Pascasarjana ISI Surakarta, Surakarta. 